\title{
The Future of Cognitive Science and the Problem of Experience
}

\author{
Mikhail A. Sushchin \\ Southwest State University, Russian Federation, 305040, Kursk, 50 let Octyabrya st., 94
}

\section{Doi:10.5901/mjss.2015.v6n6s2p74}

\begin{abstract}
Since the early 1990s a respectable interdisciplinary study of cognition and mind called cognitive science underwent a series of radical transformations. Perhaps the most dramatic one is concerned with the growing role of neuroscience with its recently announced large-scale ambitious proposals to map and simulate the activity of the whole human brain. Nevertheless it is not clear what such neuroscientific shift might entail both for the eternal questions about cognition and mind and for the cognitive movement itself. The primary aim of the article is to examine the most radical prediction about the role of neuroscience in the future cognitive studies, according to which it may eventually replace any higher-level "soft" approaches to mind and cognition. It will be shown that this scenario is implausible and unpersuasive, because though psychology needs to be grounded in neuroscientific theories and taxonomies, it is actually in no danger of elimination by those lower-level theories and approaches. Moreover, it will be noted that any reductive strategy toward mind and cognition evidently confronts a far more serious challenge of providing a satisfactory explanation for the old and treacherous puzzle of conscious experience. Finally, we will briefly outline two examples of a contemporary non-reductive informational perspective on consciousness and conclude that so as to provide a successful explanation for the whole range of mental information processing phenomena they will need further refinements and specifications.
\end{abstract}

Keywords: Cognitive Science, Cognitive Neuroscience, Eliminative Materialism, Experience, Informational Approach

\section{Introduction}

In this article we plan to address several important conceptual, methodological and epistemological issues raised by the development of cognitive neuroscience and associated complex of NBIC-convergent sciences and technologies. As contemporary philosopher of mind Ned Block has recently pointed out: "With enormous investments in neuroscience looming on the horizon, including proposals to map the activity of every neuron in the brain, it is worth asking what questions such an investment might be expected to contribute to answering. What is the likelihood that high-resolution mapping will resolve fundamental questions about how the mind works?" (Block, 2014, p. 161). Using several examples from current neuroscientific research on consciousness (including the alleged "measurement problem", i.e. problem of the finding the neural basis of consciousness and conscious experience as opposed to that of mere cognitive processing), Block concludes that without conceptually clear theories of what activations of neural assemblies might mean at the psychological level those ambitious large-scale proposals can be "of no use no matter how high the resolution" (Block, 2014, p. 164), and that it is difficult to expect any theoretical breakthroughs from passive accumulation of data alone.

Of course, similar doubts about potential outcomes of neuroscientific attempts to contribute to the study of cognition and mind are not new. For example, in the early 1980s influential computer scientist David Marr in his famous passages from «Vision» (Marr, 2010) stated that it is almost impossible to achieve an understanding of the visual perception in terms of underlying neural activity and proposed a three-level methodology of investigating the complex systems of information processing. Thus so as to understand vision, Marr thought, we need first to formulate its general computational function (which, according to Marr's definition, is in the "discovering from images what is present in the world, and where it is" (Marr, 2010, p. 3)), to define the system of representation and algorithms, by means of which those computations are expressed and carried out, and only then we can approach the level of fine-grained details of implementation of those functions and algorithms in neuronal or other substrate (this scheme was intended to encompass a broad range of computational systems, from CNS to digital computers, and even, as cognitive anthropologist Edwin Hutchins has shown (Hutchins, 1995), to some social systems). The important point of Marr's program was that he believed that the computational study of functions at the higher level can proceed quite independently of the figuring out the details of realization of those computations and algorithms in the actual mechanisms of the brain and CNS.

Based on the famous functionalist principle of multiple instantiability or multiple realizability (Putnam, 1975a, Putnam, 1975b), this ideology of autonomy of cognitive investigations from neuroscience was spread throughout the field 
of cognitive psychology in 1960-1970s, culminating in Jerry Fodor's celebrated language-like model of cognition and mind (Fodor, 1975), Chomsky's computational account of language (Chomsky, 1980), and Marr's computational theory of vision (Marr, 2010). In short, as one of the most prominent advocates of computational approach Zenon Pylyshyn has put it (Pylyshyn, 1980), cognitive systems were thought to consist of three main levels of organization (semantic, syntactic and the level of hardware), and proper tasks of cognitive psychology were assumed to lie in the sphere of description of functional/computational organization of the system, but not in matters of realization. In other words, neuroscientific accounts of implementation were believed to be irrelevant to the usual business of cognitive scientists.

But, as any standard account of the history of cognitive science would tell us, by the 1980s things began to change. With the appearance of parallel distributed processing paradigm and theory of artificial neural networks in its modern form the need and relevance of neuroscience for cognitive investigations was reassessed. Neuroscience with the invention of modern powerful techniques of neurovisualization (especially fMRI) began to dominate minds of many former "pure" cognitive psychologists, who hurried to adopt new methods for their research. But what, methodologically speaking, does this "neuromania" amount to? What can be expected from dominance of neuroscience in the context of the more general quest for traditional mysteries of consciousness, mind and cognition? Will neuroscience accommodate or maybe even eliminate more higher-level "soft" theories and approaches? What are the most treacherous obstacles on the way of such an enterprise?

Of course, the genre of this article is not apt to give full-fledged answers to all of these questions, but at least we can hope to shed a bit of light on the most significant of problems and worries, sharpened by those aforementioned American and European large-scale proposals in the brain science. And first of all in order to accomplish our aim we want to examine here one pretty well known and radical prediction about the role of neuroscience in the future cognitive and consciousness studies which we believe best captures the general line of our inquiry.

\section{Eliminativism and Cognitive Science}

On this well known and quite extreme scenario, which we primarily want to evaluate here and which we regard as central for the general purposes of the article, joint maturation, development and co-evolution of cognitive science and neuroscience can produce radical changes and maybe even demolition of that familiar and common to all us framework, by means of which we usually understand, describe and conceptualize most of our own mental life - the so called commonsense/folk psychology. This scenario, having roots in a respected philosophical tradition called eliminative materialism, in its most sophisticated form was presented in the works of philosophers Paul (Churchland, 1988) and (especially) Patricia Churchland (Churchland, 1986, Churchland 2002), who developed several important arguments in favor of embracing a co-evolutionary stance and the ideology of integrated science of cognition, mind and brain.

In her memorable 1986 book Patricia Churchland was trying to respond to two broad patterns of arguments, directed against the possibility of co-evolutionary strategy and «intertheoretic reduction», one originated from philosophical position called property dualism, according to which we have direct access to our own mental states and qualia, and the other based on the abovementioned anti-reductionism of adherents of computational cognitive science and functionalism. Following and enriching classical eliminative materialism of Sellars, Feyerabend and Quine, she was generally trying to stress that mental processes should be regarded as essentially brain processes, and that it is highly implausible that "...we can devise an adequate theory of the mind-brain without knowing in great detail about the structure and organization of nervous systems" (Churchland, 1986, p. 482).

So it would be useful for our purposes to recollect in more detail the general body of evidence, Churchland used against the skepticism of computational functionalist's camp, as we find it very relevant to issues, raised by the very recent developments in neuroscience. This line went as follows: (1) first, as she insisted, that same distinction between levels of semantic/syntactic relations and the level of implementation, usually drawn in functionalist's enterprise, is not subtle and apt for actual states of affairs in neuroscience, because in many neuroscientific inquiries the very notion of level is not homogeneous, but rather diverse: we can distinguish many different levels of organization in the brain, from molecules to synapses, to single neurons, to neural networks, to maps, to systems, and to the whole CNS (Churchland, 2002, p. 3). And, as Churchland fairly notes, "...we simply do not know at what level of organization one can assume that the physical implementation can vary, but the capacities will remain the same" (Churchland, 1986, p. 360).

On the other hand, (2) one and the same level of brain organization from a relatively higher position can be viewed as structural, but to relatively lower research level in neuroscience it can be considered functional. And this, according to Churchland's note, implies "...that one cannot foist on the brain a monolithic distinction between function and structure, and then appoint psychologists to attend to function and neuroscientists to attend to structure" (Churchland, 1986, p. 360). And it is simply not clear, why neuroscience should not be concerned with functional explanations and functional 
types of questions and why it should not possess functional theories of its own.

Of course, this is not an ultimate refutation of functional/structural distinction, but at least this critique clearly exposes shortcomings of unjustified division of labor. (3) Further evidence suggests that, although much of the everyday human cognitive activity obviously involves manipulation of symbols and the use of resources of language, it is highly implausible that the computational propositional paradigm inspired by Turing, Chomsky and the hypothesis of language of thought will be central to explaining of all possible manifestations of our cognitive toolkit, including especially perceptuomotor skills and capacities, pattern recognition, non-verbal and instrumental behavior, developmental processes and so on (that same processes that were so intensively studied in Soviet cultural-historical tradition in psychology (Vygotsky, 1986) and in the more recent alternative branch of cognitive investigations, sometimes referred to as "situated/embodied cognition" (Brooks, 1999; Clark 1997; Varela, Thompson \& Rosch, 1991; Chemero, 2009).

Finally, (4) that very fact that folk psychology may be the best available theoretical framework for psychologists and cognitive scientists now does not preclude it from systematic improvements and revision in the course of normal evolution and maturation of the science of cognition and mind. Indeed, it may turn out, and this is the key claim of all eliminativist's program (the view that was equally held and elaborated by Stephen Stich (Stich, 1996)), that those central categories of folk psychology, such as belief, desire, hope, memory, attention and so forth, by means of which we usually understand, describe and predict our mental life and behavior, will eventually (at least in part) be displaced by more adequate and refined taxonomies, notions and categories, grounded in more adequate psychological and neuroscientific frameworks and theories. In any case, as the Churchlands repeatedly stressed, this is a matter of a truly empirical inquiry, not of an armchair theorizing, and, thence, it should be evaluated and judged primarily by means of empirical science.

In sum, several things should be said about such a scenario. First, we suggest that it is more likely that cognitive science and scientific psychology of the future will yield us more precise taxonomies of mental processes and mental business in place of good old ordinary theories of mind, memory, thought, self and so on (as, for example, Tulving's famous distinction between semantic and episodic memory vividly shows - but in fact there are plenty of such examples). And those more accurate psychological concepts may find their correlates in comparable neuroscientific notions of brain business. That is, in other words, we suppose that future psychological theories can (and should) partly be grounded in relevant neuroscientific taxonomies and theories, but we find it highly implausible that this psychology (and the whole range of related psychological categories) will be fully displaced by some powerful neuroscience of the future. To borrow David Marr's famous metaphor, we need some "aerodynamics of cognitive processes", which will tell us what those processes are at the appropriate level of description and which at the same time will be, of course, much more sensitive to the simultaneous research at, so to speak, "neurophysiological level of description". This possibility neatly falls on what Churchland called "retentive end of reduction spectrum", and this is how we think things will eventually happen.

But this is not a complete story. Since brain is embedded in a physical body and body is situated in complex environment to explain the emergence of many cognitive phenomena cognitive science and neuroscience should somehow take into account an additional dimension of cognitive research, namely that one which tries to explore the possible modes of complex dynamic interplay between cognitive agents and their environments. This level of investigations in the past two decades was carried out under the name of "situated and embodied cognition". In order to account for the complexity of ways of interactions between humans and their sociocultural environments Edwin Hutchins developed a framework which he regarded as "socially distributed cognition" (Hutchins, 1995). One of the pioneers of early cognitive psychology Ulrich Neisser in his later work described this level as "ecological level of analysis" (Neisser, 1997), which, as he was trying to urge, is not in danger of elimination by neuroscience, but which instead can help to contribute to it as well as to a more traditional psychological research. Although many different names could be applied to this broad field of research (Calvo \& Gomila, 2008; Hutchins, 2010; Noe, 2004; Robbins \& Aydede, 2009) we tend to agree with Neisser and we think that in addition a reductionist's viewpoint evidently confronts one more serious bunch of problems which we now are going to describe.

\section{The Challenge of Experience}

So, if neuroscience probably does not threaten to eliminate even more traditional body of psychological investigations, what is this "ultimate problem" that we mentioned in the previous section? In brief, it is an old and well known puzzle, which was recently characterized (most notably by Thomas Nagel (Nagel, 1974) and David Chalmers (Chalmers, 1995)) as the problem of experience. Indeed, experience, or consciousness, or what is also called by many as phenomenal aspect of cognition and mental life, poses a huge and, perhaps, the most difficult problem for all contemporary sciences of mind, brain and cognition.

Nagel famously wrote, that for any conscious being we can ask a question about what it is like to be such a 
conscious being. To possess consciousness, therefore, means to have a quality of subjective character of experience or some internal point of view. His argument was, that while we can objectively study nervous systems and details behavior of beings, radically different from us, say, bats and the physiology of their perceptual apparatus, including sonars and how they orient by sonars in space, we can never take up and experience their peculiar subjective world in its entirety, neither by observation nor by imagination. And the problem of experience, Nagel insisted, is certainly unique, because in the most areas of science reduction or reductive explanation is usually accomplished by a move from a particular subjective perspective toward a greater objectivity and more neutral understanding of objects, events or phenomena. But in the case of consciousness subjectivity is precisely what needs to be explained, it is the explanandum in its own right, so any attempt to abandon those essential properties of experience in favor of traditional reductionist strategy will move us away from what we wanted to explain. Thus the paradox of conscious experience.

Nagel pessimistically noted, that at that time the status of physicalism was somewhat "...similar to that which the hypothesis that matter is energy would have had if uttered by a pre-Socratic philosopher" (Nagel 1974, p. 447). Twenty years later David Chalmers in a similar anti-reductionist vein re-emphasized the issue - he argued that standard reductive methods and theories of cognitive science and neuroscience are not sufficient to account for the gist of the problem of experience. In so doing, Chalmers introduced a distinction between, so to speak, "hard" and "easy" problems of consciousness. The latter, according to Chalmers, include, for example, explaining the abilities of a cognitive system to react to environmental stimuli, to integrate information, to give a report on the content of his or her mental states and so on: they are "easy" because they relate to the explanation of cognitive abilities, mechanisms, structures and functions. That is, to explain them, he argued, we "only" need to specify the computational or neuronal mechanism, which stands behind them, and that's where the usual methods of cognitive science and neuroscience might eventually succeed.

But over and above the mere causal explanation of cognitive phenomena and processes, Chalmers thought, we can always ask a question of why those mechanisms and functions at least sometimes are accompanied by subjective experience: "This further question is the key question in the problem of consciousness. Why doesn't all this informationprocessing go on 'in the dark', free of any inner feel? <...> There is an explanatory gap (a term due to Levine 1983) between the functions and experience, and we need an explanatory bridge to cross it" (Chalmers, 1995, p. 203). So, according to Chalmers, the really "hard" problem of consciousness is that of experience.

Rejecting principal skepticism about the unsolvability of the problem, Chalmers called for a new non-reductive naturalistic perspective on consciousness. He drew an analogy with the realm of physics where, depending upon a prevailing paradigm, certain entities are occasionally taken as fundamental and irreducible to something more elementary. Accordingly, in the context of the search for the fundamental theory of consciousness Chalmers suggested to endow experience with the same status and take it as something fundamental in our ontology. This assumption led him to the next one, namely that the emergence of experience may be understood by means of a classical information theory and the related concept of information. Thus, following Shannon's notion of information, Chalmers gave a brief sketch of his "double-aspect theory of information", according to which information at least in some of its forms may have a subjective or phenomenal aspect, at the same time being grounded in the physical world and real physical processing.

This is well known and we think that Chalmers is right to emphasize the potential of information theory as probably the best available scientific approach to experience. The main question though is how to interpret the very notion of information. For Chalmers' attributive interpretation, which states that information is some intrinsic property of the physical universe, obviously raises a whole lot of baffling questions concerning the diversity of informational processes in living and non-living systems throughout the universe, such as under which conditions information becomes consciously experienced, what it is that is distinctive about conscious information processing in comparison to many kinds of unconscious mental events, what are the simplest forms of conscious experience, which creatures should be recognized as having consciousness and so on. In this respect, for instance, it is not an exaggeration to say that even most sophisticated contemporary computational artifacts or systems of artificial intelligence are very far from having those complex types of experiences (and even "mere" cognitive capabilities!) that most humans ordinarily enjoy and Chalmers recognized that his speculations on "double-aspect" approach need several additional constraints and criteria.

Similarly a contemporary Russian philosopher David I. Dubrovskii who began to develop his theoretical approach in the early 1960s uses a category of information to describe the phenomenon of consciousness in its relation to the brain (Dubrovskii, 1971, 2007). Like Nagel, Searle, Chalmers and other antireductionists, Dubrovskii emphasizes that consciousness or, to borrow his term, subjective reality has a specific phenomenal quality that cannot be explained on the cheap in a typical eliminativist's manner. He stresses that any satisfactory account of consciousness must not sweep out intentional content and intentional nature of mental states. Since we cannot directly ascribe to consciousness "mass", "energy", spatial extension or any other basic physical attributes of all material objects and events, then how apparent causal interplay between consciousness and the brain and the body can be explained? How, for example, anything that 
escapes direct physical description can at will induce and regulate movements of the physical body and how perceptions of that body can in turn cause changes in this, as it were, "non-material stuff"?

So as to provide an explanation for this old puzzle Dubrovskii appeals a notion of information. He conjectures that with this conception in hand we can resolve those everlasting puzzles of qualitative and causative status of experiential states without resorting to untenable sorts of reductionism or dualism. In a nutshell, Dubrovskii's explanation goes like this: when, for example, we perceive the Moon or think about Mozart, we obviously do not have any small internal copies of the Moon or Mozart in our brain. What is there is only a complex distributed cerebral neurodynamic system that realizes and encodes our experiential states. Yet interpreted as information, which is always necessarily embodied in some physical form, subjective reality may govern and cause its subsequent states, thereby changing a corresponding set of states in underlying neural machinery which encodes it, namely the brain. Of course, they are not represented in any form in consciousness itself, because I obviously do not know, phenomenologically speaking, what is going on in my brain when I am thinking about Mozart or experiencing anything else, but in some sense thanks to the transformations in consciousness I can to some degree indirectly govern states of my own brain and their dynamics. So when consciousness goes from one state to the other, or when an agent, for instance, decides to raise his hand and initiates subsequent movements, it is because, Dubrovskii points out, consciousness may be understood as some form of information, and information may serve as a factor of control and regulation in complex self-organizing biological systems. But precisely what form?

Dubrovskii's answer is this: unlike Chalmers he suggests that information processing may be restricted only to the living, technical and sociocultural systems, and only to the creatures with sufficiently complex nervous systems we can ascribe some form of mental organization. Information does not go on "in the dark" when it is subjected to other higherorder informational processes and in the evolutionary sophistication of this process of creation and representing of information about information may be traced the origins of language-mediated human subjective reality, which is, according to Dubrovskii, probably the most complex form of informational control of behavior and cognition. He believes that though this choice might be less intriguing metaphysically, it is nevertheless far better suited for empirical verification and possible corrections.

\section{Conclusion}

Thus, to summarize, we should say that while the informational paradigm might seem the most promising scientific framework for explaining experience, it is now actually needs many additional specifications and criteria that can clarify a whole host of questions that were partially outlined in the previous section. Indeed, why do even most sophisticated contemporary computers and robots evidently lack experience or self-consciousness? What is it that makes informationprocessing in many living systems so rich and hard to explain? What is special about unconscious information processing? How does unconscious information processing become consciously experienced? What, after all, is human conscious information processing?

There are plenty of lasting questions that cannot be even posed here. The question we started with was concerned with the potential role neuroscience may play in the future cognitive investigations, especially with respect to other disciplines and approaches as well as to those fundamental questions, which engrossed minds of philosophers for centuries. Thus we scrutinized one notable account of reduction of psychology to neuroscience and concluded that it is unlikely that someday psychological or any other higher-level body of generalizations about the mind will be completely replaced by some future neuroscientific theories and frameworks. So we can expect that in the long run neuroscience driven by the complex of converging sciences and technologies will play a preeminent role in uncovering the so called neural correlates of consciousness and experience (though this term was subjected to a sharp philosophical critique (Noe \& Thompson, 2004)), and it will surely tell us much about the character of human information processing despite the skepticism of early computational cognitivism, but in order to account for the riddle of experience neuroscience along with a whole branch of contemporary cognitive disciplines will probably need a conceptual breakthrough, such as that which once led to the rise of computer era, cybernetics, information theory, and early developments in cognitive science. It may be that, as Christof Koch and Gary Marcus recently hypothesized (Koch \& Marcus, 2014), the "hard problem" of consciousness will eventually be transformed into more tractable ones and even disappear in the same way, as the problem of "what is life" was faded away and replaced by simpler problems, but by now experience is still a huge problem both for science and for philosophy. 


\section{Acknowledgements}

This work is supported by the Russian Scientific Fund, Grant no. 15-18-10013 "Socio-anthropological dimensions of convergent technologies".

\section{References}

Block, N. (2014). Consciousness, Big Science, and Conceptual Clarity. In G. Marcus \& J. Freeman (Eds.), The Future of the Brain: Essays by the World's Leading Neuroscientists (pp. 161-176). Princeton: Princeton University Press.

Brooks, R. A. (1999). Cambrian Intelligence: The Early History of the New Al. Cambridge, MA: MIT Press.

Calvo, P., \& Gomila, T. (Eds.). (2008). Handbook of Cognitive Science: An Embodied Approach. San Diego, CA: Elsevier.

Chalmers, D. J. (1995). Facing Up to the Problem of Consciousness. Journal of Consciousness Studies, 2, pp. 200-219.

Chemero, A. (2009). Radical Embodied Cognitive Science. Cambridge, MA: MIT Press.

Chomsky, N. (1980). Rules and representations. The Behavioral and Brain Sciences, 3, pp. 1-15.

Churchland, P. M. (1988). Matter and Consciousness. Cambridge, MA: MIT Press.

Churchland, P. S. (1986). Neurophilosophy: Toward a Unified Science of the Mind-Brain. Cambridge, MA: The MIT Press.

Churchland, P. S. (2002). Brain-Wise: Studies in Neurophilosophy. Cambridge, MA: The MIT Press.

Clark, A. (1997). Being There: Putting Bain, Body and World Together Again. Cambridge, MA: MIT Press.

Dubrovskii, D. I. (1971). Psikhicheskie yavleniya i mozg [Mental Phenomena and Brain]. Moscow, USSR: Izdatel'stvo "Nauka".

Dubrovskii, D. I. (2007). Soznanie, mozg, iskusstvennyi intellekt [Consciousness, Brain, Artificial Intelligence]. Moscow, Russia: ID Strategiya-Tsentr.

Fodor, J. (1975). The Language of Thought. New York: Crowell.

Hutchins, E. (1995). Cognition in the Wild. Cambridge, MA: The MIT Press.

Hutchins, E. (2010). Cognitive Ecology. Topics in Cognitive Science, 2, pp. 705-715.

Koch, C., \& Marcus, G. (2014). Neuroscience in 2064: A Look at the Last Century. In G. Marcus \& J. Freeman (Eds.), The Future of the Brain: Essays by the World's Leading Neuroscientists (pp. 255-269). Princeton: Princeton University Press.

Levine, J. (1983). Materialism and Qualia: The Explanatory Gap. Pacific Philosophical Quarterly, 64, pp. 354-361.

Marr, D. (2010). Vision: An Informational Investigation into the Human Representation and Processing of Visual Information. Cambridge, MA: The MIT Press.

Nagel, T. (1974). What Is It Like to Be a Bat? The Philosophical Review, 83, pp. 435-450.

Neisser, U. (1997). The Future of Cognitive Science: An Ecological Analysis. In D. M. Johnson \& C. E. Erneling (Eds.), The Future of the Cognitive Revolution. New York: Oxford University Press.

Noe, A. (2004). Action in Perception. Cambridge, MA: The MIT Press.

Noe, A., \& Thompson, E. (2004). Are There Neural Correlates of Consciousness? Journal of Consciousness Studies, 11, pp. 3-28.

Putnam, H. (1975a). The mental life of some machines. In Mind, Language and Reality, Philosophical Papers, Vol. 2. (pp. 408-428). Cambridge: Cambridge University Press.

Putnam, H. (1975b). The nature of mental states. In Mind, Language and Reality, Philosophical Papers, Vol. 2. (pp. 429-440). Cambridge: Cambridge University Press.

Pylyshyn, Z. W. (1980). Computation and cognition: issues in the foundations of cognitive science. The Behavioral and Brain Sciences, 3, pp. 111-134.

Robbins, P., \& Aydede, M. (Eds.). (2009). The Cambridge Handbook of Situated Cognition. Cambridge: Cambridge University Press.

Stich, S. (1996). Deconstructing the Mind. New York: Oxford University Press.

Varela, F., Thompson, E., \& Rosch, E. (1991). The Embodied Mind: Cognitive Science and Human Experience. Cambridge, MA: MIT Press.

Vygotsky, L. S. (1986). Thought and Language (A. Kozulin, Trans.). Cambridge, MA: MIT Press. 